\title{
Short-chain fatty acid formation in the hindgut of rats fed oligosaccharides varying in monomeric composition, degree of polymerisation and solubility
}

\author{
Ulf Nilsson* and Margareta Nyman \\ Applied Nutrition and Food Chemistry, Center for Chemistry and Chemical Engineering, Lund University, PO Box 124, SE-221 O0 LUND, \\ Sweden
}

(Received 31 January 2005 - Revised 20 May 2005 - Accepted 27 May 2005)

\begin{abstract}
The contents of short-chain fatty acids were investigated in rats fed lactitol, lactulose and four fructo-oligosaccharides of different degree of polymerisation and solubility. Fructo-oligosaccharides with a low degree of polymerisation (2-8) generated the highest levels of butyric acid all along the hindgut, whereas fructo-oligosaccharides with a high degree of polymerisation (10-60) generated the highest levels of propionic acid. These specific differences were also generally reflected in the caecal pools and molar proportions of short-chain fatty acids. The lower solubility of the fructo-oligosaccharides was related to a lower degree of caecal fermentation. Lactulose and lactitol yielded high proportions of acetic acid and low proportions of butyric acid. It is concluded that both the degree of polymerisation and the solubility may affect short-chain fatty acid formation, whereas the fructose content per se seem to be of less importance. This may be of interest when designing foods with specific health effects.
\end{abstract}

Short-chain fatty acids: Fructo-oligosaccharides: Lactulose: Lactitol

When indigestible carbohydrates are fermented in the human colon, short-chain fatty acids (SCFAs; mainly acetic, propionic and butyric acids) and gases $\left(\mathrm{CO}_{2}, \mathrm{CH}_{4}\right.$ and $\left.\mathrm{H}_{2}\right)$ are formed. Several studies have shown that some of these acids have positive effects on health, one of the most important effects being the trophic effect on the intestinal epithelium, through a stimulation of blood flow and mucosal proliferation, and thus a decrease in the risk of mucosal damage (Mortensen et al. 1990, 1991). Butyric acid, and to some extent also propionic acid, is an important energy substrate for the colonic mucosa (Roediger, 1980; Cummings \& Macfarlane, 1991). It has therefore been suggested that these acids increase the resistance to diseases in the colon, such as ulcerative colitis (Cummings, 1997) and colonic cancer (Scheppach et al. 1992). Furthermore, butyric acid can inhibit the proliferation of colon cancer cells in vitro (Scheppach et al. 1995). Propionic acid has also been reported to have metabolic effects, through inhibiting hepatic cholesterol synthesis from acetic acid, and the higher the propionic:acetic acid ratio, the more beneficial the effects (Wolever et al. 1991). Usually, only the formation of acetic, propionic and butyric acid during fermentation is reported, but other SCFA are also formed. Some of these acids, for example the branched acids that are formed by the fermentation of indigestible proteins and not from carbohydrates (Salminen et al. 1998), have been associated with negative effects.

All SCFA have a lowering effect on $\mathrm{pH}$, which may be beneficial as such. For example, mineral complexes that are insoluble at a physiological $\mathrm{pH}$ may be partly solubilised at a lower $\mathrm{pH}$ and therefore more easily absorbed through the colonic mucosa (Younes et al. 1996). The motility of the colon may also be influenced to some extent by SCFA, but other parts of the gastrointestinal tract are probably more affected (Cherbut et al. 1997). Furthermore, a lower $\mathrm{pH}$ is known to inhibit the bacterial transformation of primary to secondary bile acids (Nagengast et al. 1988).

Different types of indigestible carbohydrate have been shown to produce different SCFA patterns (Brighenti et al. 1989; Berggren et al. 1993; Casterline et al. 1997). One explanation of this could be differences in the monomeric composition of the carbohydrates. For example, both resistant starch fractions and $\beta$-glucans have been shown to provide high amounts of butyric acid, whereas plant material containing a high amount of pectins seems to be a particularly good source of acetic acid (Brighenti et al. 1989; Berggren et al. 1993). Results, however, are not conclusive, and other factors also seem to be of importance, for example the complexity of the food matrix and a combination of substrates (Henningsson et al. 2002). Furthermore, the types of linkage may have an effect, and $\beta$-glucans and resistant starch have been shown to give rise to different SCFA profiles when using the same in vitro system (Casterline et al. 1997).

Another explanation might be the degree of polymerisation (DP). Fructo-oligosaccharides have been shown to form high amounts of butyric acid in several studies on rats (Casterline et al. 1997; Le Blay et al. 1999). However, in one study, large amounts of propionic acid were reported (Levrat et al. 1991). As there are indications that fructo-oligosaccharides with

Abbreviations: CA, carboxylic acid; DP, degree of polymerisation; IN, long-chain inulin; IN-ls, long-chain inulin with a low solubility; Mix OF-IN, mixture of OF and IN; $\mathrm{OF}$, oligofructose; SCFA, short-chain fatty acid.

* Corresponding author: Ulf Nilsson MSc , fax +46 46222 4532, email Ulf.Nilsson@inl.lth.se 
a longer chain (inulin) were used in the latter study, it could be speculated that this was due to the higher DP of inulin. The site of fermentation has also been shown to be different for different types of carbohydrate, and more resistant fibres seem to be fermented more in the distal part of the colon (Henningsson et al. 2002). This is interesting as most colonic diseases also occur at this site.

The aim of the present investigation was to study the distribution and content of SCFA formed in various parts in the hindgut of rats given various indigestible carbohydrates with a different DP. The amounts of lactic acid and succinic acid were also quantified. For this purpose, four types of fructo-oligosaccharide were chosen for the study: oligofructose with a DP between 2 and 8, inulin with an average DP of 23 (10-60), which was also available in a variant that had a lower solubility, and finally a mixture of oligofructose and inulin. The fructooligosaccharides chosen were extracted from chicory root, and the polymers consisted of fructose monomers with $\beta-2,1$ glycosidic linkages that were not hydrolysed by human digestive enzymes (Franck, 2002). A fructose-containing disaccharide (lactulose, galactose and fructose with $\beta-1,4$ linkages) was also included in the study, as was lactitol (galactose and glucitol with $\beta-1,4$ linkages) as it has a composition similar to that of lactulose. Both these disaccharides reach the colon, where they are fermented.

\section{Materials and methods}

\section{Materials}

Fructo-oligosaccharides derived from chicory root with a different DP were obtained from ORAFTI (Tienen, Belgium): Raftilose P95 (oligofructose; OF) consisting of oligofructose with a DP between 2 and 8, Raftiline HP (long-chain inulin; IN) and Raftiline HPX (long-chain inulin with a low solubility; IN-ls), with a somewhat higher molecular weight, i.e. an average DP of 23 (10-60) (Franck, 2002). Raftiline HPX has a lower solubility $\left(1 \mathrm{~g} / 1\right.$ at $\left.25^{\circ} \mathrm{C}\right)$ than Raftiline HP $\left(20 \mathrm{~g} / 1\right.$ at $\left.25^{\circ} \mathrm{C}\right)$ and a higher gel strength in fat substitution applications according to the manufacturer's product sheets (ORAFTI).

Raftilose SYNERGY1, a mixture of OF and IN (1:1; Mix OFIN), was also included; this consisted of a mixture of DP 10-60 and DP $2-8$. OF is produced by the partial enzymatic hydrolysis of naturally occurring inulin extracted from the chicory root, whereas IN is obtained by removing fructo-oligosaccharides of a low DP from natural inulin (Franck, 2002). By modifying the powder characteristics in the subsequent spray-drying process, an inulin with lower solubility (IN-ls) and different functionality is obtained.

Two disaccharides were also investigated: lactulose, which is a disaccharide consisting of fructose and galactose (Calbiochem, Darmstadt, Germany), and lactitol, which consists of galactose and glucitol (Danisco, Copenhagen, Denmark).

\section{Animals and diets}

Male Wistar rats, 3-4 weeks old, were used in the experiments, seven in each group. One group of rats was fed a control diet containing no indigestible carbohydrates (Table 1). The control diet contained casein (Sigma Chemical Company, St Louis, MO, USA) as protein source, sucrose (Danisco Sugar, Malmö,
Table 1. Composition of test diets ( $\mathrm{g} / \mathrm{kg}$ dry weight)

\begin{tabular}{lcc}
\hline Component & Control & Test diets \\
\hline Fructo-oligosaccharides, lactitol, lactulose & - & $80-86 \cdot 9 \S$ \\
Casein & 120 & 120 \\
DL-Methionine & $1 \cdot 2$ & $1 \cdot 2$ \\
Maize oil & 50 & 50 \\
Mineral mixture $†$ & 48 & 48 \\
Vitamin mixture $\ddagger$ & 8 & 8 \\
Choline chloride & 2 & 2 \\
Sucrose & 100 & 100 \\
Wheat starch & $670 \cdot 8$ & $583 \cdot 9-590 \cdot 8 \|$ \\
\hline
\end{tabular}

†Containing $(\mathrm{g} / \mathrm{kg}) 0.37 \mathrm{CuSO}_{4} .5 \mathrm{H}_{2} \mathrm{O}, 1.4 \mathrm{ZnSO}_{4} .7 \mathrm{H}_{2} \mathrm{O}, 332.1 \mathrm{KH}_{2} \mathrm{PO}_{4}, 171.8 \mathrm{NaH}_{2}$ $\mathrm{PO}_{4} .2 \mathrm{H}_{2} \mathrm{O}, 324.4 \mathrm{CaCO}_{3}, 0.068 \mathrm{KI}, 57.2 \mathrm{MgSO}_{4}, 7.7 \mathrm{FeSO}_{4} .7 \mathrm{H}_{2} \mathrm{O}, 3.4 \mathrm{MnSO}_{4} . \mathrm{H}_{2} \mathrm{O}$, $0.020 \mathrm{CoCl} .6 \mathrm{H}_{2} \mathrm{O}, 101.7 \mathrm{NaCl}$.

¥Containing $(\mathrm{g} / \mathrm{kg}) 0.62$ menadion, 2.5 thiamine hydrochloride, 2.5 riboflavin, 1.25 pyridoxine hydrochloride, 6.25 calcium pantothenate, 6.25 nicotinic acid, 0.25 folic acid, 12.5 inositol, $1.25 p$-aminobenzoic acid, 0.05 biotin, 0.00375 cyanocobalamin, 0.187 retinol palmitate, 0.00613 calciferol, $25 \mathrm{~d}$ - $\alpha$-tocopheryl acetate, 941.25 maize starch.

§ Purity of the oligosaccharides $92-100 \%$ (dry weight).

|| Depending on the purity of the added oligosaccharide.

Sweden), maize oil (Mazola, Bestfoods Nordic A/S, Copenhagen, Denmark), DL-methionine (Sigma Chemical Company), choline chloride (Aldrich Chemie, Steinheim, Germany), a mineral mixture (Apoteket, Malmö, Sweden), a vitamin mixture (Apoteket, Malmö, Sweden) and wheat starch (Lundbergs, Malmö, Sweden). Wheat starch can be expected to be completely digested and absorbed, and does not contribute to any hindgut fermentation (Björck et al. 1987). In the test diets, the oligosaccharides were substituted for wheat starch to a level of $80 \mathrm{~g}$ indigestible carbohydrate/kg diet (dry weight; Table 1).

The feed intake was restricted to $12 \mathrm{~g}$ dry weight/d, and water was given ad libitum. The rats were allowed $7 \mathrm{~d}$ to adapt to the diet, which was followed by a $5 \mathrm{~d}$ long experimental period during which faeces and feed residues were collected daily. The faeces were stored at $-20^{\circ} \mathrm{C}$ and then freeze-dried and milled before being analysed for any remaining indigestible carbohydrates. The animals were killed using $\mathrm{CO}_{2}$ narcosis, and the caecum and proximal and distal colon were removed. Caecal tissue weight, content and $\mathrm{pH}$ were measured directly, and the different parts of the hindgut were frozen and stored at $-40^{\circ} \mathrm{C}$ until analysis.

The Ethics Committee for Animal Studies at Lund University approved the animal experiments.

\section{Analysis}

Carboxylic acids. A GLC method was used to analyse the amount of SCFAs (formic, acetic, propionic, isobutyric, butyric, isovaleric, valeric, caproic, heptanoic acids). Other carboxylic acids (CAs) quantified with that method were lactic acid and succinic acid (Richardson et al. 1989). The intestinal content and the faecal samples were homogenised (using a Polytron; Kinematica, Luzern Switzerland) together with an internal standard (2-ethylbutyric acid; Sigma Chemical Company). Hydrochloric acid was added to protonise the SCFAs and to be able to extract them in diethylether. After being silylated with $n$-(tert-butyldimethylsilyl)- $n$-methyltrifluoroacetamide (Sigma Chemical Company), the samples were allowed to stand for $48 \mathrm{~h}$ to complete derivatisation. Samples were then injected onto an HP-5 column (GLC, HP 6890; Hewlett Packard, Wilmington, DE, USA). Chem Station software (Hewlett Packard) was used for the analysis. 
Indigestible carbohydrates. The amounts of fructo-oligosaccharides, lactitol and lactulose in the raw material were suggested to be as determined by the manufacturers. The amount of fructooligosaccharide in the faeces was first estimated enzymatically (number 139106; Boehringer Mannheim, Mannheim Germany) after hydrolysis in perchloric acid $\left(0.6 \mathrm{M}, 15 \mathrm{~min}, 80^{\circ} \mathrm{C}\right)$ (Nilsson \& Björck, 1988). Only rats fed IN and IN-ls had detectable amounts of fructose in their faeces. The amounts of fructo-oligosaccharide in the faeces from these rats were therefore also quantified with a more reliable method, the AOAC method 999.03 (McCleary et al. 2000).

In this method, fructo-oligosaccharides are treated with fructanase (exo-inulinase), and the amount of fructose is quantified with the R-hydroxy-benzoic acid hydrazine reducing-sugar method. Lactitol and lactulose in the faeces were extracted in ethanol $(1: 1, \mathrm{v} / \mathrm{v})$ for $30 \mathrm{~min}$ at room temperature according to a previously developed method (Ekvall et al. 2005). Arabinose was used as the internal standard. The sugars were then analysed by high-performance anion-exchange chromatography with pulsed amperometric detection (Dionex 500; Dionex, Sunnyvale, CA, USA), and $\mathrm{NaOH}(15-200 \mathrm{mmol})$ was used as the eluent with a flow rate of $1.0 \mathrm{ml} / \mathrm{min}$.

Calculations and statistical evaluation. The design of the experiment resulted in one control group and six test diets containing the different indigestible carbohydrates. All analyses were performed at least in duplicate. The maximum error of the analyses was less than $5 \%$.

DM digestibility was calculated as:

$$
1-\frac{\mathrm{g} \text { dry matter in faeces }}{\mathrm{g} \text { dry matter-ingested }}
$$

The caecal pools of CAs were calculated as the levels of each acid $(\mu \mathrm{mol} / \mathrm{g})$ multiplied by the weight of the caecal content. The values were extrapolated to a complete intake of indigestible carbohydrates $(4.8 \mathrm{~g})$ and thus corrected for the small amount of feed residue.

Minitab statistical software (Release 13.32 Minitab Inc. State college, PA, USA) was used for statistical evaluation of the results, and a general linear model (ANOVA) followed by Tukey's procedure for multiple comparisons was used to find significant differences $(P<0 \cdot 05)$ between means. The results in Fig. 1 were evaluated with the two-sample student's $t$ test $(P<0 \cdot 05)$.

\section{Results}

Weight gain, feed intake, caecal pH and faecal weight

The feed intake was almost complete (91-100\%), and the gain in body weight differed only for the rats fed $\mathrm{OF}$, which exhibited a higher weight gain than rats fed lactitol, lactulose or IN-ls (Table 2). Adding indigestible carbohydrates to the control diet increased the caecal content from $0.8 \mathrm{~g}$ to a mean of $2.3 \mathrm{SE}$ $0 \cdot 1 \mathrm{~g}(P<0 \cdot 05)$. The caecal content was highest for rats fed lactitol $(2 \cdot 8 \mathrm{~g})$ and lowest for those fed IN-ls $(1.8 \mathrm{~g})$. Rats fed the other test diets had intermediate caecal contents $(2 \cdot 1-2 \cdot 3 \mathrm{~g})$. The caecal $\mathrm{pH}$ of rats given the control diet was 7.0. Mix OF-IN resulted in the most accentuated fall in $\mathrm{pH}$, to about 6.4 , whereas the other oligosaccharides resulted in a pH between 6.6 and 6.9 (Table 2).

The faecal fresh weight was highest in rats fed IN and IN-ls: 3.7 and $4.1 \mathrm{~g} / 5 \mathrm{~d} v$. mean $2.8 \mathrm{SE} 0.2 \mathrm{~g} / 5 \mathrm{~d}$ and $1.7 \mathrm{~g} / 5 \mathrm{~d}(P<0.05)$ for the other test diets and the control diet, respectively
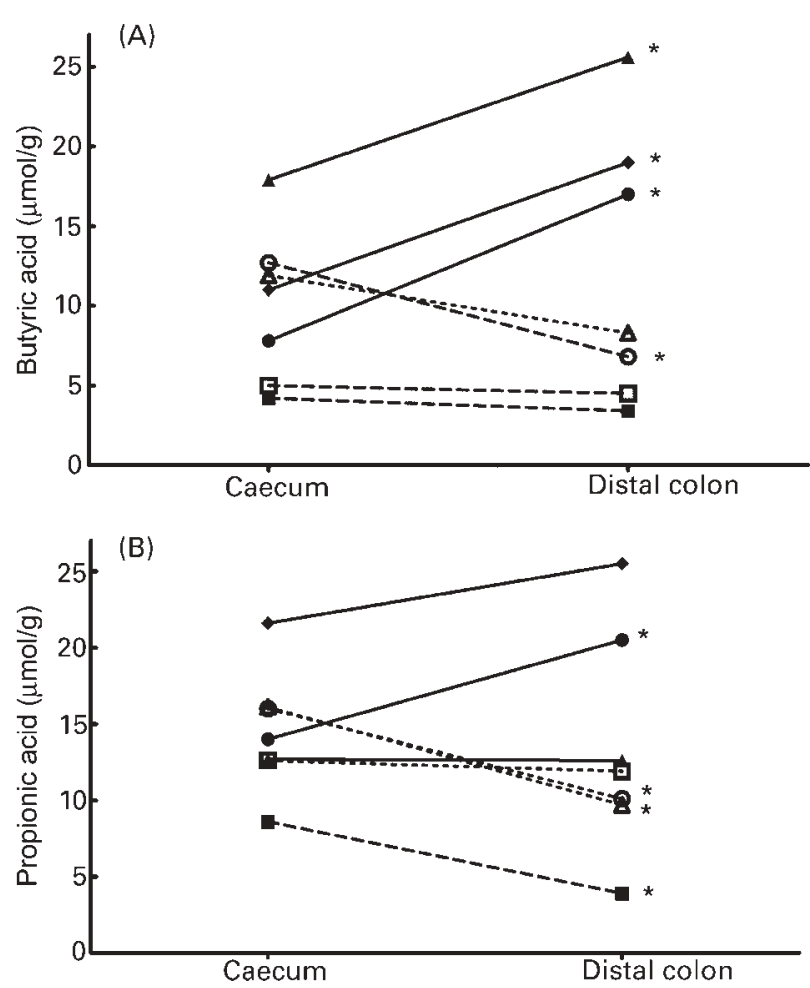

Fig. 1. Level ( $\mu \mathrm{mol} / \mathrm{g}$ wet content) in the caecum and distal colon of rats: (A) butyric acid and (B) propionic acid. ( $\square$ ) Control, ( $\square$ ) lactitol, ( $\Delta$ ) lactulose, $(\boldsymbol{\Delta})$ oligofructose, $(\bigcirc)$ mixture of oligofructose and long-chain inulin, $(\bullet)$ longchain inulin, and $(\bullet)$ long-chain inulin with low solubility. *Levels in the distal colon are significantly different from those in the caecum $(P<0.05)$.

(Table 2). Thus, the bulking index (i.e. the fresh faecal increment in $\mathrm{g} / \mathrm{g}$ indigestible carbohydrate ingested) was 0.4 and 0.5 for IN and IN-1s, respectively, $v .0 \cdot 2-0 \cdot 3$ in rats fed the other test diets (data not shown). The faecal dry weight was also higher for rats fed IN $(2.7 \mathrm{~g} / 5 \mathrm{~d})$ and IN-ls $(3.0 \mathrm{~g} / 5 \mathrm{~d})$, but only the result for IN-ls was significant $(P<0.05)$, compared with rats fed lactitol and $\mathrm{OF}(2 \cdot 1 \mathrm{~g} / 5 \mathrm{~d}$ and $2 \cdot 2 \mathrm{~g} / 5 \mathrm{~d}$, respectively; Table 2$)$. The faecal dry weight increment per $\mathrm{g}$ ingested indigestible carbohydrate was on average 0.3 for IN-ls and IN in comparison with a mean of 0.1 for lactitol and OF (data not shown).

The DM digestibility decreased when fructo-oligosaccharides were added to the diet $(P<0 \cdot 05)$, whereas lactitol and lactulose gave DM digestibility values similar to those of the control group. Rats fed IN-ls also showed a lower DM digestibility than rats fed lactulose and lactitol $(P<0 \cdot 05)$. IN-ls was somewhat more resistant to fermentation than IN, as judged by the higher faecal excretion of fructo-oligosaccharides with IN-ls $(0.44 \mathrm{~g} / 5 \mathrm{~d}$ compared with $0.07 \mathrm{~g} / 5 \mathrm{~d} \mathrm{~g}$ with $\mathrm{IN}$; data not shown).

\section{Carboxylic acids in the hindgut of rats}

Caecal pool of carboxylic acids. The caecal pool of CAs was 2-4 times higher in the rats fed the test diets than in those fed the control diet without any indigestible carbohydrates (Table 3). There was, however, considerable variation between the groups fed the different test diets $(97-188 \mu \mathrm{mol})$. The major acids formed were acetic acid $(51-94 \mu \mathrm{mol})$, propionic acid $(23-48 \mu \mathrm{mol})$ and butyric acid $(9-43 \mu \mathrm{mol})$, these acids accounting for $81-93 \%$ of the total amount of CAs analysed. 
Table 2. Feed intake, body weight gain, caecal content and $\mathrm{pH}$, faecal weights and DM digestibility (DMD) in rats fed a control diet and test diets containing lactulose and lactitol and fructo-oligosaccharides with various degrees of polymerisation (DP) and solubility

(Values are means with their standard errors for seven rats per diet)

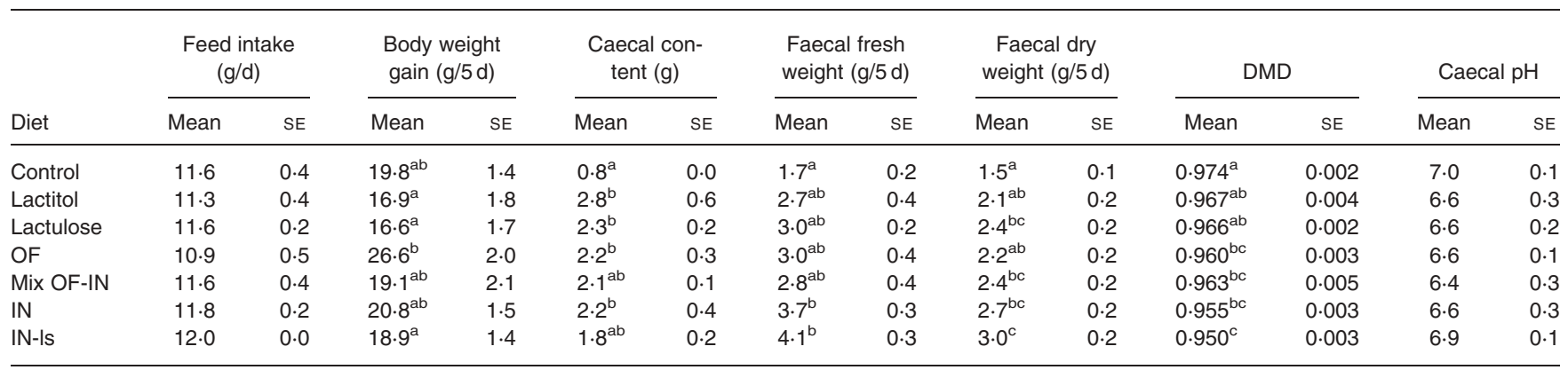

OF, Raftilose P95 (ORAFTI) fructo-oligosaccharides with a DP between 2 and 8 . IN and IN-ls, Raftiline HP and Raftiline HPX, both with an average DP of 23 (10-60), in which IN-Is has a lower solubility. Mix OF-IN, Raftilose SYNERGY1, a mixture of DP 2-8 (OF) and 10-60 (IN) (1:1).

a,b,c Mean values within a column with unlike superscript letters were significantly different $(P<0.05)$.

The remaining part could be attributed to lactic acid (1-5\%), succinic acid $(2-10 \%)$ and isobutyric acid (1-2\%; data not shown).

Rats fed lactitol and IN-ls had a lower caecal pool of CA (mean 97 and $98 \mu \mathrm{mol}$, respectively) than rats fed the other test diets (173 SE $9 \mu \mathrm{mol} ; P<0 \cdot 05$ ). This was due to a lower content of all three main SCFA, and as a consequence these two substrates showed the lowest amount of propionic (mean $24 \mu \mathrm{mol}$ ) and butyric acid (mean $10 \mu \mathrm{mol}$ ). Furthermore, the caecal pool of butyric acid was higher in rats fed OF $(43 \mu \mathrm{mol})$ than in those fed the disaccharides and the other fructo-oligosaccharides (9-27 $\mu \mathrm{mol}$; $P<0.05$ ), whereas IN and Mix OF-IN had the highest caecal pools of propionic acid (46 and $48 \mu \mathrm{mol} v$. 23-33 $\mu \mathrm{mol}$ with the other test diets).

Levels of carboxylic acids in the hindgut. Rats fed lactulose had the highest levels of CAs in the caecum $(90 \mu \mathrm{mol} / \mathrm{g})$, whereas rats fed lactitol and IN-ls had the lowest levels $(53 \mu \mathrm{mol} / \mathrm{g}$ and $60 \mu \mathrm{mol} / \mathrm{g}$, respectively; $P<0.05$; Table 4$)$. The highest level of butyric acid was found in rats fed the diet containing OF (18 $\mu \mathrm{mol} / \mathrm{g}$ v. $5-13 \mu \mathrm{mol} / \mathrm{g}$ for the other test diets; $P<0.05$ ), whereas the highest level of propionic acid was found in rats fed the IN diet $(22 \mu \mathrm{mol} / \mathrm{g} v .13-16 \mu \mathrm{mol} / \mathrm{g}$ for the other test diets; $P<0 \cdot 05)$. Lactulose was found to generate the highest amount of acetic acid in the caecum of rats $(45 \mu \mathrm{mol} / \mathrm{g})$, which was significantly higher than the value for rats fed the other test diets except IN.
Similar tendencies could generally be seen in the proximal and distal colon (Table 4), with lactulose giving the highest level of acetic acid, OF the highest level of butyric acid and IN the highest level of propionic acid.

There was a higher level of butyric acid in the distal part of colon than in the caecum of rats fed OF, IN and IN-ls $(P<0.05)$, whereas it decreased or was similar with the other test diets (Fig. 1 (A)). With regard to propionic acid, the level increased in groups fed IN and IN-ls $(P<0.05$; Fig. 1 (B)).

Low caecal levels of lactic acid $(1-4 \mu \mathrm{mol} / \mathrm{g})$ and succinic acid $(2-9 \mu \mathrm{mol} / \mathrm{g}$ ) were also identified, for which lactulose, OF and Mix OF-IN produced the highest amount of succinic acid (6$9 \mu \mathrm{mol} / \mathrm{g}$; Fig. 2). Only small amounts of formic acid, isobutyric acid, isovaleric acid, valeric acid, caproic acid and heptanoic acid $(0 \cdot 1-1 \cdot 1 \mu \mathrm{mol} / \mathrm{g}$ ) could be found in caecum (Fig. 3).

Distribution of acetic, propionic and butyric acid in hindgut. The highest molar proportions of propionic acid in the caecum were seen in rats fed IN $(30 \%, v$. a mean of $25 \pm 1 \%$ for the other oligosaccharides), whereas rats fed OF generated the highest proportions of butyric acid ( $31 \%$. v. 15 SE $2 \%$ for rats fed the other substrates; $P<0 \cdot 05$; Table 4). These differences were also seen in the colon. High proportions of butyric acid were, however, also seen in the distal part of the colon $(P<0.05)$ of rats fed $\mathrm{IN}+\mathrm{ls}$ and IN. Furthermore, rats fed lactulose generally had rather low proportions of propionic acid and butyric acid, and

Table 3. Caecal pools ( $\mu \mathrm{mol}$ ) of carboxylic acids in rats fed a control diet and test diets containing lactulose and lactitol and fructo-oligosaccharides with various degrees of polymerisation (DP) and solubility

(Values are means with their standard errors for seven rats per diet)

\begin{tabular}{|c|c|c|c|c|c|c|c|c|c|c|}
\hline \multirow[b]{2}{*}{ Diet } & \multicolumn{2}{|c|}{ Acetic acid } & \multicolumn{2}{|c|}{ Propionic acid } & \multicolumn{2}{|c|}{ Butyric acid } & \multicolumn{2}{|c|}{ Lactic acid } & \multicolumn{2}{|c|}{ Total } \\
\hline & Mean & SE & Mean & SE & Mean & SE & Mean & SE & Mean & SE \\
\hline Control & $26 \cdot 6^{a}$ & $2 \cdot 2$ & $6 \cdot 6^{\mathrm{a}}$ & 0.5 & $3.2^{a}$ & 0.4 & $2 \cdot 1^{a}$ & 0.3 & $42 \cdot 3^{a}$ & 3.5 \\
\hline Lactitol & $55 \cdot 1^{\mathrm{ab}}$ & $4 \cdot 6$ & $24 \cdot 6^{\mathrm{b}}$ & $1 \cdot 2$ & $9 \cdot 3^{a}$ & 0.7 & $1.5^{\mathrm{a}}$ & 0.2 & $97.4^{\mathrm{ab}}$ & $5 \cdot 0$ \\
\hline Lactulose & $93 \cdot 8^{\mathrm{C}}$ & 9.9 & $33 \cdot 2^{\mathrm{bc}}$ & $3 \cdot 1$ & $24.9^{b c}$ & 3.6 & $3 \cdot 8^{\mathrm{ab}}$ & 0.5 & $187 \cdot 7^{\mathrm{C}}$ & $17 \cdot 4$ \\
\hline OF & $74.0^{\mathrm{bc}}$ & $12 \cdot 4$ & $31.9^{b c}$ & 3.7 & $42 \cdot 7^{d}$ & $4 \cdot 8$ & $1.8^{\mathrm{a}}$ & 0.8 & $171 \cdot 5^{\mathrm{C}}$ & $21 \cdot 1$ \\
\hline Mix OF-IN & $76 \cdot 3^{b c}$ & 9.4 & $47 \cdot 7^{\mathrm{C}}$ & 9.7 & $27 \cdot 0^{c}$ & 3.0 & $8 \cdot 1^{\mathrm{b}}$ & 3.1 & $176 \cdot 4^{\mathrm{C}}$ & $21 \cdot 1$ \\
\hline IN & $74.6^{\mathrm{bc}}$ & $7 \cdot 0$ & $45 \cdot 7^{c}$ & $5 \cdot 1$ & $24 \cdot 4^{b c}$ & $2 \cdot 7$ & $3 \cdot 7^{\mathrm{ab}}$ & 0.9 & $155 \cdot 2^{\mathrm{bc}}$ & $13 \cdot 3$ \\
\hline IN-ls & $51 \cdot 3^{\mathrm{ab}}$ & $2 \cdot 5$ & $22 \cdot 9^{b}$ & $1 \cdot 3$ & $12 \cdot 9^{\mathrm{ab}}$ & 0.9 & $2 \cdot 1^{\mathrm{a}}$ & 0.4 & $97 \cdot 9^{\mathrm{b}}$ & $4 \cdot 3$ \\
\hline
\end{tabular}

OF, Raftilose P95 (ORAFTI) fructo-oligosaccharides with a DP between 2 and 8. IN and IN-Is, Raftiline HP and Raftiline HPX, both with an average DP of $23(10-60)$, in which IN-Is has a lower solubility. Mix OF-IN, Raftilose SYNERGY1, a mixture of DP 2-8 (OF) and $10-60(\mathrm{IN})(1: 1)$.

${ }^{\mathrm{a}, \mathrm{b}, \mathrm{c}} \mathrm{c}$ Mean values within a column with unlike superscript letters were significantly different $(P<0.05)$. 
Table 4. Levels of carboxylic acids ( $\mu \mathrm{mol} / \mathrm{g}$ wet content) and distribution between acetic, propionic and butyric acids (\%) in different parts of the hindgut of rats fed diets containing lactulose, lactitol and fructo-oligosaccharides with various degrees of polymerisation (DP) and solubility

(Values are means with their standard errors for seven rats per diet)

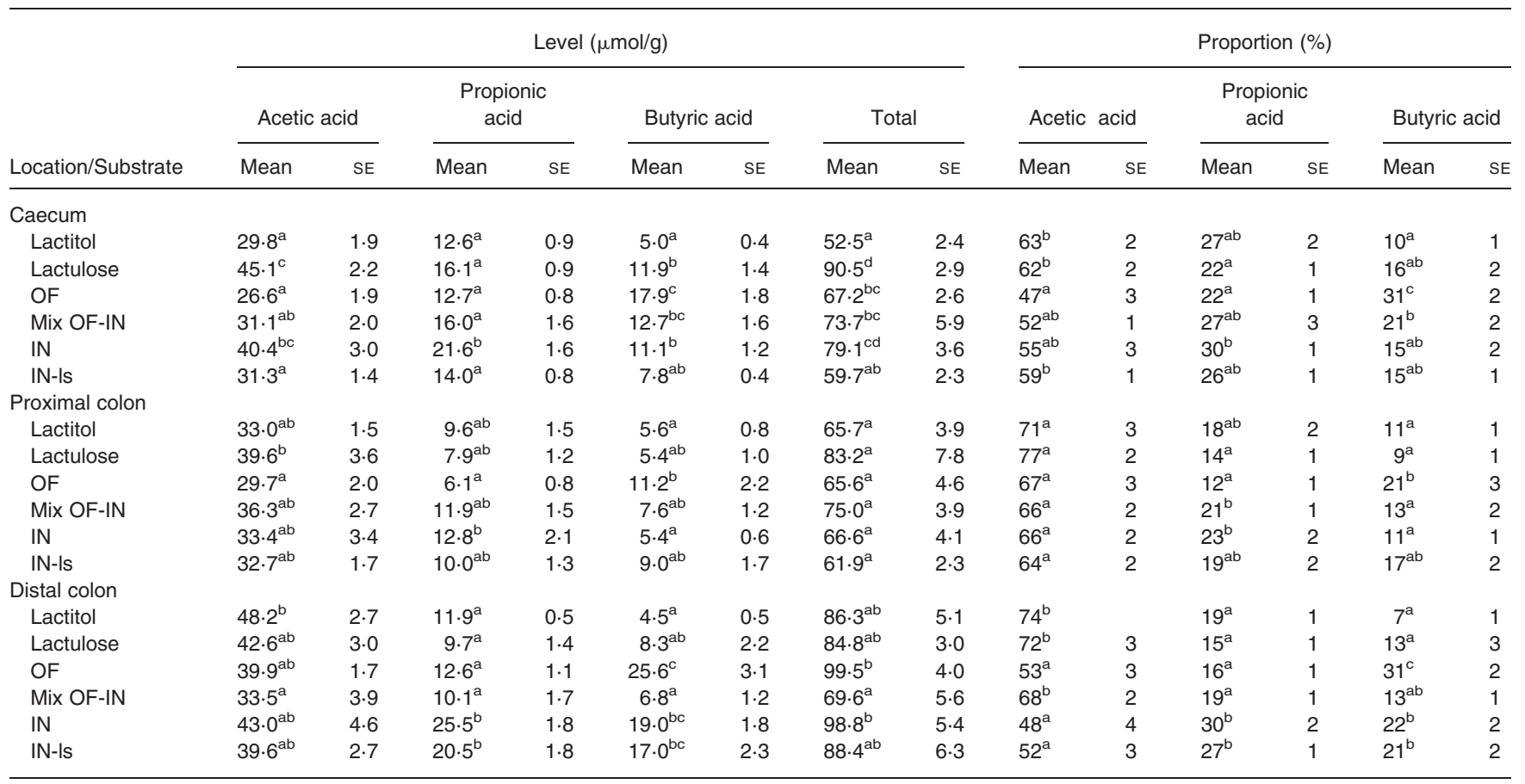

OF, Raftilose P95 (ORAFTI) fructo-oligosaccharides with a DP between 2 and 8 . IN and IN-Is, Raftiline HP and Raftiline HPX both with an average DP of 23 (10-60), in which IN-ls has a lower solubility. Mix OF-IN, Raftilose SYNERGY1, a mixture of DP 2-8 (OF) and 10-60 (IN) (1:1).

a,b,c,d Mean values within a column and the same part of the hindgut with unlike superscripts are significantly different $(P<0.05)$.

high proportions of acetic acid, throughout the hindgut. Comparatively high proportions of both butyric acid and propionic acid were found in the caecum of rats fed Mix OF-IN

Caecal content and morphology. Feeding rats with diets containing indigestible carbohydrates increased the caecal wet content considerably compared with a control diet without any indigestible carbohydrates. The caecal tissue weight was related to caecal wet content $\left(R^{2}=0 \cdot 81\right)$, whereas no such relationship could be seen with caecal CA levels $\left(R^{2}=0 \cdot 49\right.$; Fig. 4).

\section{Discussion}

There is evidence that butyric and propionic acids may have health-promoting effects, and as the formation of SCFAs from carbohydrates in the colon appears to differ, it is of interest to study whether it is possible to alter SCFA formation by dietary means. In the present study, four types of fructo-oligosaccharide, lactulose and lactitol were used to study the potential effects of monomeric composition, DP and the solubility of the carbohydrates on SCFA formation, using a rat model. It can be

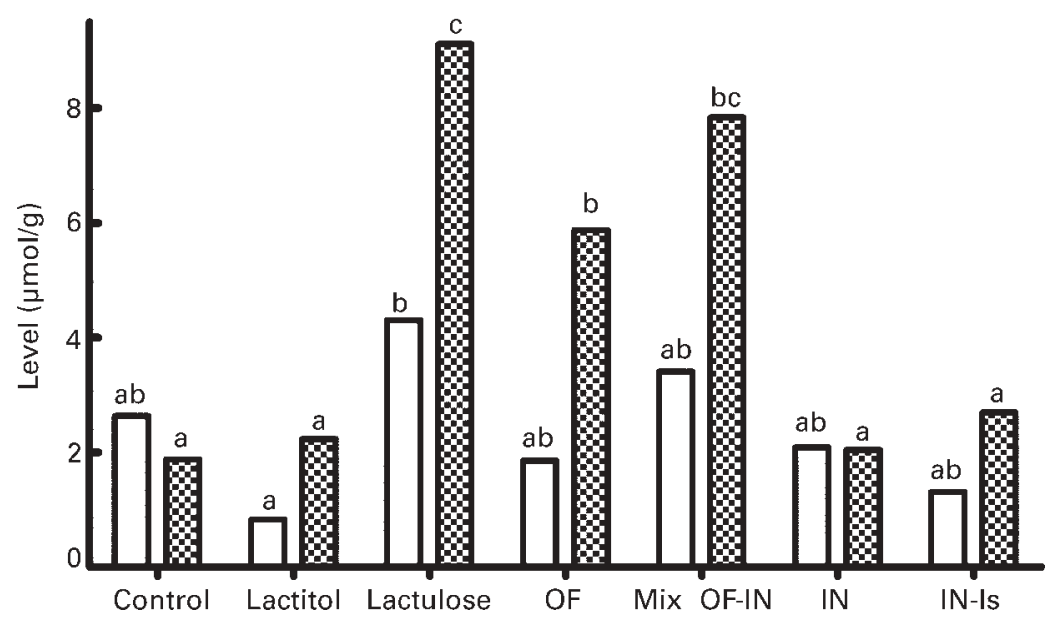

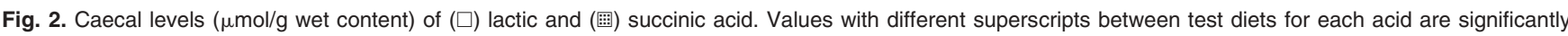
different $(P<0.05)$ 


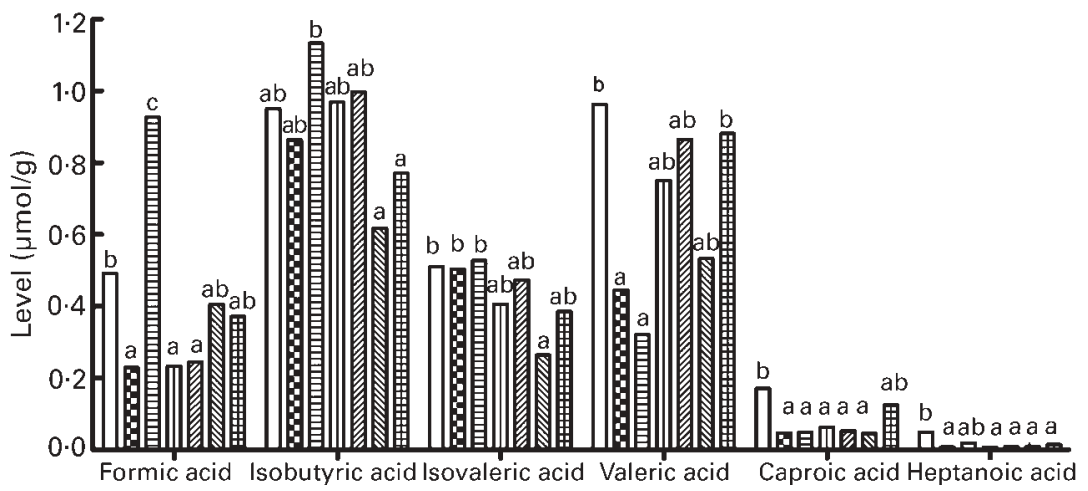

Fig. 3. Caecal levels ( $\mu \mathrm{mol} / \mathrm{g}$ wet content) of formic, isobutyric, isovaleric, valeric, caproic and heptanoic acids. ( $\square$ ) Control, (国) lactitol, (目) lactulose, (四) oligofructose (OF), (ख) mixture of oligofructose and long-chain inulin (Mix OF-IN), ( $\mathbb{\otimes}$ ) long-chain inulin (IN), ( $\boxplus$ ) long-chain inulin with low solubility (IN-Is). Values with different superscripts between test diets for each acid are significantly different $(P<0.05)$.

argued that the digestive tract of rats differs from that of man. However, it is difficult to study SCFA production in humans as the proximal colon, where most of the fermentation takes place, is inaccessible. Therefore, the rat is commonly used as an in vivo model. The rat model used in the present study has been shown to correlate well with studies in man with respect to total fermentability and bulking capacity (Nyman et al. 1986). Furthermore, in vitro fermentation has been shown to give similar SCFA profiles with faecal inocula from human subjects and rats (Lupton \& Villalba, 1988; Barry et al. 1995), indicating that the rat is a relevant model for this purpose.
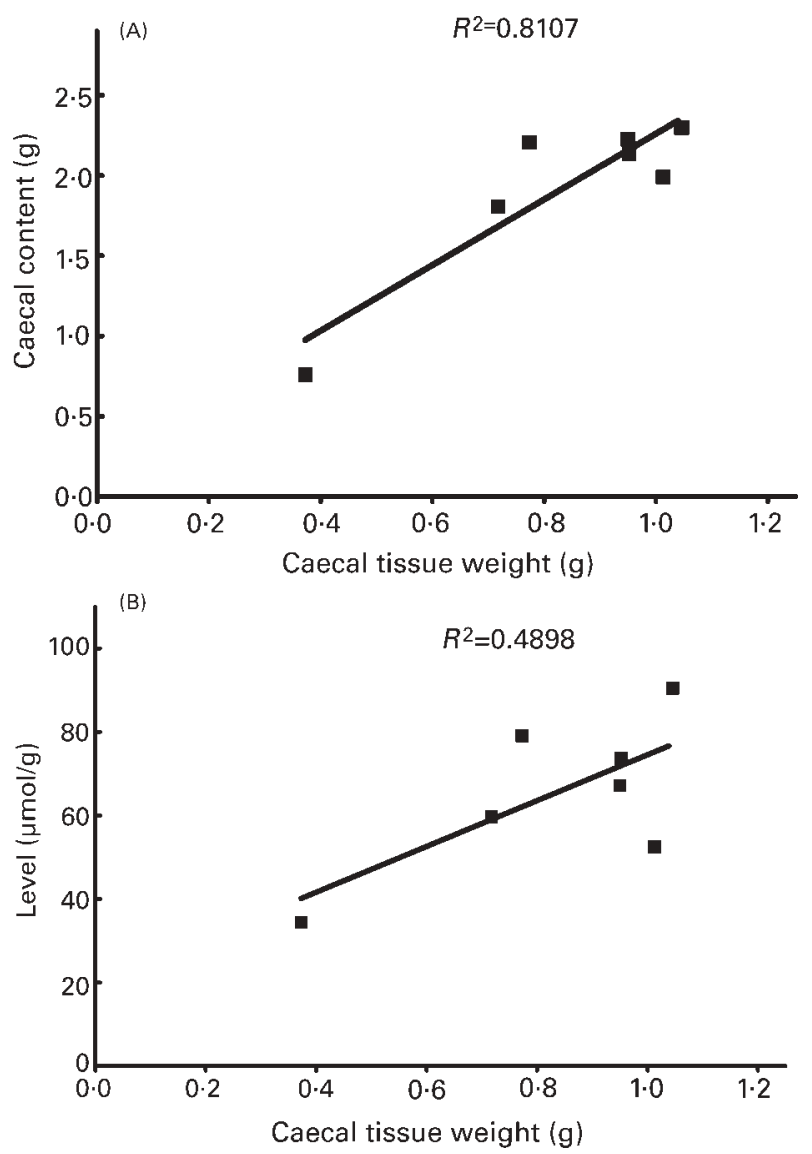

Fig. 4. Correlation between caecal tissue weight and (A) caecal wet content, and $(B)$ total levels of carboxylic acids in the caecum
Feeding rats with diets containing oligosaccharides increased the caecal wet content considerably compared with a control diet without any indigestible carbohydrates. Interestingly, caecal tissue weight was correlated to a higher degree with caecal content than with caecal CA level $\left(R^{2}=0.81 v\right.$. $\left.R^{2}=0.49\right)$, indicating that the hypertrophic effect observed in rats fed oligosaccharides was mainly due to increased caecal content rather than the formation of CAs. Similar observations have been made by others (Wyatt et al. 1988; Kishida et al. 2001) and explained by an increase in mechanical stress (Calvert et al. 1989). It has, however, also been suggested that the caecal enlargement is associated with an increase in mucosal cell proliferation, which is stimulated by SCFAs mediated by a systemic mechanism in vivo (Sakata, 1987). Furthermore, an increased production of SCFAs may increase proglucagon mRNA expression and the secretion of glucagon-like peptide-2, which are other factors affecting mucosal cell proliferation (Massimino et al. 1998). SCFA enemas have also been shown to have a transmural trophic effect and preserve the mucosal surface area of dysfunctional and atrophic colon in rats (Kissmeyer-Nielsen et al. 1995).

Diets containing IN and IN-ls led to higher faecal wet and dry weights than diets containing the other oligosaccharides. Both these carbohydrates had a higher DP than the other test materials. Interestingly, similar results have been found in vitro, where fructo-oligosaccharides with a DP greater than 10 were fermented much more slowly than fructo-oligosaccharides with a DP of less than 10 (Roberfroid et al. 1998). Furthermore, IN-ls, with a lower solubility than IN, was somewhat more resistant to hindgut fermentation, as judged by the higher faecal excretion of oligosaccharides with IN-ls than with IN. Feeding with IN-ls led to the lowest caecal pool of CAs $(98 \mu \mathrm{mol} v .168 \pm 8 \mu \mathrm{mol}$ with the other fructo-oligosaccharides; Table 3), suggesting that IN-1s is fermented to a greater extent in the distal part of the hindgut. IN-ls was also the substrate that gave the highest caecal $\mathrm{pH}$ (6.9 v. a mean of $6 \cdot 6 \pm 0.1$ for the other oligosaccharides; Table 2), providing further evidence of a higher resistance to caecal fermentation of this oligosaccharide than the others.

Another substrate that led to comparatively low caecal pools of CAs was lactitol, indicating a low degree of fermentation. However, feeding rats with this substrate gave the highest caecal content. An explanation of this could be that unfermented lactitol contributes to the osmosis in the caecum to a higher extent than SCFAs. Water would then be retained rather than absorbed 
from the caecum, resulting in an enlarged, distended organ. Feeding rats with lactulose, on the other hand, resulted in the highest caecal levels and pools of CA, indicating that this disaccharide is rapidly fermented. Interestingly, in studies on humans lactulose resulted in more pronounced changes in, for example, SCFA production and the activity of pro-carcinogenic enzymes compared with lactitol (Ballongue et al. 1997), as well as to a lower colonic pH (5.1 v. 5.6 with lactitol; Patil et al. 1987).

The effects on microbial composition also seem to be different between these two disaccharides. Thus, lactulose has been shown to selectively stimulate the number of bifidobacteria in man (Tuohy et al. 2002), whereas lactitol decreased the bifidobacterial and Bacteroides populations in an in vitro culture system when added to a growth medium containing a low amount of dietary fibre (Probert et al. 2004). In the same in vitro model, oligofructose was shown to increase the number of bifidobacteria, bacteria that have been proven to have a probiotic potential in man (Gibson \& Wang, 1994). However, contrary to the present study, lactitol was more prone to producing butyric acid than oligofructose (Probert et al. 2004).

Lactulose generally had low levels and proportions of propionic acid, and high levels and proportions of acetic acid (Table 4). This may have metabolic consequences, as propionic acid has been suggested to lower serum lipid and cholesterol levels. Thus, when subjects were given rectal infusions of propionate and acetate, it was shown that propionate repressed the utilisation of acetate for the synthesis of cholesterol (Wolever et al. 1991). Similar results were obtained in obese rats (Berggren et al. 1996). Interestingly, in a human study on healthy subjects, lactulose was shown to increase serum lipids and LDL-cholesterol (Jenkins et al. 1991), and the speculation is whether this was due to the high amounts of acetic acid formed. In a study on non-insulin-dependent diabetic patients, serum total and LDL-cholesterol were lowered by fructooligosaccharides (Yamashita et al. 1984). The discrepancies in result between fructo-oligosaccharides and lactulose were suggested to be due to a higher propionate acetate: ratio with fructo-oligosaccharides than with lactulose (Luo et al. 1996). Another explanation could be differences in metabolic status between healthy and non-insulin-dependent subjects.

Rats fed diets containing OF had the highest caecal pools and levels of butyric acid, whereas rats fed diets containing IN had the highest caecal pools (together with Mix OF-IN) and levels of propionic acid. As both of these carbohydrates are composed of fructose with $\beta-2,1$ linkages it seems that other factors, such as DP, are of importance. OF consists of fructo-oligosaccharides with a DP between 2 and 8, whereas IN contains fructo-oligosaccharides with a DP of between 10 and 60. In most studies, fructo-oligosaccharides have been found to give high yields of butyric acid, at least compared with other oligosaccharides (Roland et al. 1995; Campbell et al. 1997; Poulsen et al. 2002). However, in one study employing different doses of inulin (fructo-oligosaccharides with a higher DP), high proportions of propionic acid were formed (Levrat et al. 1991). High amounts of propionic acid with IN were also obtained in rats fed fibre diets partially replaced by fructo-oligosaccharides (IN or oligofrucotse; Kleessen et al. 2001). However, the levels of butyric acid were in the same range as the two fructo-oligosaccharides, which was higher than with the control diet in that study. This could be explained by the fact that the diet contained other indigestible carbohydrates. It has thus been shown that certain combinations of indigestible carbohydrates yielded a higher proportion of butyric acid than did the single substrates (Henningsson et al. 2002). Rats fed a diet containing $\mathrm{OF}$ also gained most in weight. Fermentable carbohydrates are known to provide energy to the host (6.3$7 \cdot 1 \mathrm{~kJ} / \mathrm{g}$ ) (Livesey et al. 1995; Roberfroid, 1999). However, in this study all carbohydrates tested are easily fermented. It can therefore be questioned whether the SCFA profile could be of importance in this context.

The butyric acid level increased along the hindgut of rats fed OF, IN and IN-ls. Similar results were observed for propionic acid in rats fed IN and IN-ls. The transit time through the gastrointestinal tract has been reported to influence bacterial activities and pathways and, as a result, the proportion of individual SCFAs may be changed (Oufir et al. 2000). It has been reported that the shorter the caecal transit time, the higher the proportion of butyric acid (Mathers \& Dawson, 1991). As the transit time was not measured in the present study, it remains to be shown whether this is also the case for OF, IN and IN-ls. The increased level of butyric acid along the hindgut in rats fed IN-ls may also be due to the slower fermentation of this substrate. Wheat bran, another substrate that is slowly fermented, has been shown to lead to large amounts of butyric acid in the distal part of the hindgut (Henningsson et al. 2002). This is interesting and might be important from a nutritional point of view, as most colonic diseases also occur in the distal part of colon.

We conclude that the DP and solubility of the fructo-oligosaccharides are of great importance for the SCFA formation. Oligosaccharides with a low DP (OF) generated a high level of butyric acid, whereas those with a high DP (IN) gave a high level of propionic acid. A lower solubility of the fructo-oligosaccharides was related to a lower degree of caecal fermentation and a higher formation of butyric acid in the distal part of colon. This means that different types of fructo-oligosaccharides can be used for different health effects when designing foods. The fructose content per se seems to be of less importance as lactulose, containing galactose and fructose, and lactitol (galactose and glucitol) both yielded high proportions of acetic acid and low proportions of butyric acid.

\section{Acknowledgements}

This study was carried out with the financial support of the Commission of the European Communities specific Research and Technological Development programme 'Quality of Life and Management of Living Resources', QLK1-2000-300042, PROTECH. It does not necessarily reflect the views of the Commission and in no way anticipates its future policy in this area. Fructo-oligosaccharides and lactitol were kindly provided by ORAFTI (Belgium) and Danisco (Finland), respectively. The authors thank Marianne Stenberg for her invaluable technical assistance.

\section{References}

Ballongue J, Schumann C \& Quignon P (1997) Effects of lactulose and lactitol on colonic microflora and enzymatic activity. Scand J Gastroenterol Suppl 222, 41-44.

Barry JL, Hoebler C, Macfarlane GT, Macfarlane S, Mathers JC, Reed KA, Mortensen PB, Nordgaard I, Rowland IR \& Rumney CJ (1995) Estimation of the fermentability of dietary fibre in vitro: a European interlaboratory study. Br J Nutr 74, 303-322.

Berggren AM, Björck IME, Nyman EMGL \& Eggum BO (1993) Shortchain fatty-acid content and ph in cecum of rats given various sources of carbohydrates. J Sci Food Agric 63, 397-406. 
Berggren AM, Nyman EM, Lundquist I \& Björck IM (1996) Influence of orally and rectally administered propionate on cholesterol and glucose metabolism in obese rats. Br J Nutr 76, 287-294.

Björck I, Nyman M, Pedersen B, Siljeström M, Asp NG \& Eggum BO (1987) Formation of enzyme resistant starch during autoclaving of wheat starch: studies in vitro and in vivo. J Cereal Sci 6, 159-172.

Brighenti F, Testolin G, Canzi E, Ferrari A, Wolever TMS, Ciappellano S, Porrini M \& Simonetti P (1989) Influence of long-term feeding of different purified dietary-fibers on the volatile fatty-acid (VFA) profile, $\mathrm{pH}$ and fiber-degrading activity of the cecal contents in rats. Nutr Res $\mathbf{9}$, $761-772$

Calvert RJ, Otsuka M \& Satchithanandam S (1989) Consumption of raw potato starch alters intestinal function and colonic cell proliferation in the rat. $J$ Nutr 119, 1610-1616.

Campbell JM, Fahey GC Jr \& Wolf BW (1997) Selected indigestible oligosaccharides affect large bowel mass, cecal and fecal short-chain fatty acids, pH and microflora in rats. $J$ Nutr 127, 130-136.

Casterline JL, Oles CJ \& Ku Y (1997) In vitro fermentation of various food fiber fractions. J Agric Food Chem 45, 2463-2467.

Cherbut C, Aube AC, Blottiere HM \& Galmiche JP (1997) Effects of short-chain fatty acids on gastrointestinal motility. Scand J Gastroenterol 32, Suppl. 222, 58-61.

Cummings JH (1997) Short-chain fatty acid enemas in the treatment of distal ulcerative colitis. Eur J Gastroenterol Hepatol 9, 149-153.

Cummings JH \& Macfarlane GT (1991) The control and consequences of bacterial fermentation in the human colon. J Appl Bacteriol 70, 443-459.

Ekvall J, Stegmark R \& Nyman M (2005) Content of low molecular weight carbohydrates in vining peas (Pisum sativum) after blanching and freezing: effect of cultivar and cultivation conditions. J Sci Food Agric 85, 691-699.

Franck A (2002) Technological functionality of inulin and oligofructose. Br J Nutr 87, Suppl. 2, S287-S291.

Gibson GR \& Wang X (1994) Bifidogenic properties of different types of fructo-oligosaccharides. Food Microbiol 11, 491-498.

Henningsson AM, Björck IM \& Nyman EM (2002) Combinations of indigestible carbohydrates affect short-chain fatty acid formation in the hindgut of rats. J Nutr 132, 3098-3104.

Jenkins DJ, Wolever TM, Jenkins A, et al. (1991) Specific types of colonic fermentation may raise low-density-lipoprotein-cholesterol concentrations. Am J Clin Nutr 54, 141-147.

Kishida T, Nogami H, Himeno S \& Ebihara K (2001) Heat moisture treatment of high amylose cornstarch increases its resistant starch content but not its physiologic effects in rats. $J$ Nutr 131, 2716-2721.

Kissmeyer-Nielsen P, Mortensen FV, Laurberg S \& Hessov I (1995) Transmural trophic effect of short chain fatty acid infusions on atrophic, defunctioned rat colon. Dis Colon Rectum 38, 946-951.

Kleessen B, Hartmann L \& Blaut M (2001) Oligofructose and long-chain inulin: influence on the gut microbial ecology of rats associated with a human faecal flora. Br J Nutr 86, 291-300.

Le Blay G, Michel C, Blottiere HM \& Cherbut C (1999) Prolonged intake of fructo-oligosaccharides induces a short-term elevation of lactic acidproducing bacteria and a persistent increase in cecal butyrate in rats. J Nutr 129, 2231-2235.

Levrat MA, Remesy C \& Demigne C (1991) High propionic acid fermentations and mineral accumulation in the cecum of rats adapted to different levels of inulin. $J$ Nutr 121, 1730-1737.

Livesey G, Smith T, Eggum BO, Tetens IH, Nyman M, Roberfroid M, Delzenne N, Schweizer TF \& Decombaz J (1995) Determination of digestible energy values and fermentabilities of dietary fibre supplements: a European interlaboratory study in vivo. Br J Nutr 74, 289-302.

Luo J, Rizkalla SW, Alamowitch C, et al. (1996) Chronic consumption of short-chain fructooligosaccharides by healthy subjects decreased basal hepatic glucose production but had no effect on insulin-stimulated glucose metabolism. Am J Clin Nutr 63, 939-945.
Lupton JR \& Villalba N (1988) Fermentation of fiber to short chain fattyacids - a comparative-study with humans, baboons, pigs and rats. FASEB J 2, A1201-A1201.

McCleary BV, Murphy A \& Mugford DC (2000) Measurement of total fructan in foods by enzymatic/spectrophotometric method: collaborative study. J AOAC Int 83, 356-364.

Massimino SP, McBurney MI, Field CJ, Thomson AB, Keelan M, Hayek MG \& Sunvold GD (1998) Fermentable dietary fiber increases GLP-1 secretion and improves glucose homeostasis despite increased intestinal glucose transport capacity in healthy dogs. J Nutr 128, 1786-1793.

Mathers JC \& Dawson LD (1991) Large bowel fermentation in rats eating processed potatoes. Br J Nutr 66, 313-329.

Mortensen FV, Hessov I, Birke H, Korsgaard N \& Nielsen H (1991) Microcirculatory and trophic effects of short chain fatty acids in the human rectum after Hartmann's procedure. Br J Surg 78, $1208-1211$.

Mortensen FV, Nielsen H, Mulvany MJ \& Hessov I (1990) Short chain fatty acids dilate isolated human colonic resistance arteries. Gut 31, $1391-1394$.

Nagengast FM, Hectors MP, Buys WA \& van Tongeren JH (1988) Inhibition of secondary bile acid formation in the large intestine by lactulose in healthy subjects of two different age groups. Eur J Clin Invest 18, 56-61.

Nilsson U \& Björck I (1988) Availability of cereal fructans and inulin in the rat intestinal tract. J Nutr 118, 1482-1486.

Nyman M, Asp NG, Cummings J \& Wiggins H (1986) Fermentation of dietary fibre in the intestinal tract: comparison between man and rat. Br J Nutr 55, 487-496.

Oufir LE, Barry JL, Flourie B, Cherbut C, Cloarec D, Bornet F \& Galmiche JP (2000) Relationships between transit time in man and in vitro fermentation of dietary fiber by fecal bacteria. Eur J Clin Nutr 54, 603-609.

Patil DH, Westaby D, Mahida YR, Palmer KR, Rees R, Clark ML, Dawson AM \& Silk DB (1987) Comparative modes of action of lactitol and lactulose in the treatment of hepatic encephalopathy. Gut 28, 255-259.

Poulsen M, Molck AM \& Jacobsen BL (2002) Different effects of shortand long-chained fructans on large intestinal physiology and carcinogen-induced aberrant crypt foci in rats. Nutr Cancer 42, 194-205.

Probert HM, Apajalahti JH, Rautonen N, Stowell J \& Gibson GR (2004) Polydextrose, lactitol, and fructo-oligosaccharide fermentation by colonic bacteria in a three-stage continuous culture system. Appl Environ Microbiol 70, 4505-4511.

Richardson AJ, Calder AG, Stewart CS \& Smith A (1989) Simultaneous determination of volatile and non-volatile acidic fermentation products of anaerobes by capillary gas-chromatography. Lett Appl Microbiol 9, $5-8$.

Roberfroid MB (1999) Caloric value of inulin and oligofructose. J Nutr 129, S1436-S1437.

Roberfroid MB, Van Loo JA \& Gibson GR (1998) The bifidogenic nature of chicory inulin and its hydrolysis products. J Nutr 128, 11-19.

Roediger WE (1980) The colonic epithelium in ulcerative colitis: an energy-deficiency disease? Lancet 2, 712-715.

Roland N, Nugon-Baudon L, Andrieux C \& Szylit O (1995) Comparative study of the fermentative characteristics of inulin and different types of fibre in rats inoculated with a human whole faecal flora. Br J Nutr 74, $239-249$.

Sakata T (1987) Stimulatory effect of short-chain fatty acids on epithelial cell proliferation in the rat intestine: a possible explanation for trophic effects of fermentable fibre, gut microbes and luminal trophic factors. Br J Nutr 58, 95-103.

Salminen S, Bouley C, Boutron-Ruault MC, et al. (1998) Functional food science and gastrointestinal physiology and function. Br J Nutr 80, Suppl. 1, S147-S171.

Scheppach W, Bartram HP \& Richter F (1995) Role of short-chain fatty acids in the prevention of colorectal cancer. Eur J Cancer 31A 1077-1080. 
Scheppach W, Sommer H, Kirchner T, Paganelli GM, Bartram P, Christl S, Richter F, Dusel G \& Kasper H (1992) Effect of butyrate enemas on the colonic mucosa in distal ulcerative colitis. Gastroenterology 103, 51-56.

Tuohy KM, Ziemer CJ, Klinder A, Knöbel Y, Pool-Zobel BL \& Gibson GR (2002) A human volunteer study to determine the prebiotic effects of lactulose powder on human colonic microbiota. Microb Ecol Health Dis 14, 165-173.

Wolever TM, Spadafora P \& Eshuis H (1991) Interaction between colonic acetate and propionate in humans. Am J Clin Nutr 53, 681-687.
Wyatt GM, Horn N, Gee JM \& Johnson IT (1988) Intestinal microflora and gastrointestinal adaptation in the rat in response to non-digestible dietary polysaccharides. Br J Nutr 60, 197-207.

Yamashita K, Kawai K \& Itakura M (1984) Effects of fructo-oligosaccharides on blood-glucose and serum-lipids in diabetic subjects. Nutr Res 4, 961-966.

Younes H, Demigne C \& Remesy C (1996) Acidic fermentation in the caecum increases absorption of calcium and magnesium in the large intestine of the rat. Br J Nutr 75, 301-314. 